\title{
EDUCAÇÃO SEXUAL E DOCÊNCIA: AS RELAÇÕES DE GÊNERO, A DIVERSIDADE E A SEXUALIDADE DENTRO DA ESCOLA
}

\author{
SEX EDUCATION AND TEACHING: THE GENDER RELATIONS, DIVERSITY AND \\ SCHOOL IN SEXUALITY
}

\author{
Paula Camila ARGENTI ${ }^{1}$ \\ Débora Raquel da Costa MILANI ${ }^{2}$
}

\begin{abstract}
RESUMO: Com este artigo pretendemos: evidenciar a necessidade de considerar a educação de forma plural, não unidimensionalizando e subordinando os educandos a esquemas monolíticos e iconoclastas que geram a "educação praxeológica". Ao contrário, observamos a imprescindibilidade da autorreflexão dos docentes e a emergência de trabalhar as relações de gênero, a diversidade e a sexualidade dentro da escola, junto à comunidade escolar, e evidenciar o enlace e o comprometimento da educação com a educação sexual. Para a realização da pesquisa utilizou-se como metodologia a hermenêutica filosófica da Escola de Grenoble (antropologia do imaginário, antropologia das organizações educativas e socioantropologia do cotidiano): leituras e grades interpretativas de análise de textos segundo as técnicas hermenêuticas.
\end{abstract}

PALAVRAS-CHAVE: Escola. Educação sexual. Paradigmaholonômico.

ABSTRACT: With this article we aim to: highlight the need to consider education plural, not unidimensionalizando and subordinating the students the Monolithic and iconoclastic schemes that generate the "praxeological education". On the contrary, we observe the indispensability of self-reflection of teachers and emergency work gender relations, diversity and sexuality within the school, with the school community, and highlight the link and commitment of education with sex education. For the research methodology was used as the philosophical hermeneutics of the School of Grenoble (imaginary anthropology, anthropology of educational organizations and everyday socioanthropology): readings and interpretive grid analysis of texts according to the hermeneutic techniques.

KEYWORDS: School. Sex education. Holonomic paradigm.

\section{Introdução}

\footnotetext{
${ }^{1}$ Universidade Estadual Paulista (Unesp), Faculdade de Ciências e Letras, Araraquara - SP - Brasil. Mestranda no Programa de Pós-Graduação em Educação Sexual. E-mail: paulaargenti_rp@ hotmail.com.

${ }^{2}$ Universidade Estadual Paulista (Unesp), Faculdade de Ciências e Letras, Araraquara - SP - Brasil. Docente no Programa de Pós-Graduação em Educação Sexual. E-mail: deb.milani@yahoo.com.br.
} 
De acordo com os Parâmetros Curriculares Nacionais (BRASIL, 1997) é papel da escola construir relações de confiança para que o educando possa perceber-se e viver, antes de mais nada, como ser em formação, e para que a manifestação de características culturais que partilhe com seu grupo de origem possa ser trabalhada como parte de suas circunstâncias de vida, não impedindo assim, o seu desenvolvimento pessoal, que também vai sendo construído.

Os PCNs (BRASIL, 1997) abordam a necessidade de tratar a diversidade cultural reconhecendo-a e valorizando-a para a superação das discriminações. A escola tem papel fundamental nesse processo, pois: é o espaço em que pode se dar a convivência entre educandos de origem e nível socioeconômico diferentes. Na escola são ensinadas as regras do espaço público para o convívio democrático com a diferença. É no ambiente escolar que se apresenta aos educandos os conhecimentos sistematizados sobre o país e o mundo e são fornecidos subsídios para debates e discussões em torno de questões sociais.

Assim, a escola ocupa lugar essencial na vida das crianças e adolescentes e na construção de sua identidade. Deve garantir acesso a informações sobre temas ligados à sexualidade, direitos e deveres, relações de gênero, entre outros.

Dado o caráter social da sexualidade é imprescindível que todos os educadores estejam envolvidos na adoção de uma perspectiva mais abrangente de sexualidade e possam ter uma postura mais aberta de escuta e trabalhar com os educandos: respeito, interesse, motivação e interação.

Inserindo-nos nos estudos antropológicos do imaginário, busca-se neste artigo, evidenciar a necessidade de considerar a criança e sua educação de forma ampla e as relações na cotidianidade escolar,não unidimensionalizando e subordinando a esquemasmonolíticos e iconoclastas, pois o inconoclasmo induz a repressão do imaginário e a "educação praxeológica". Tudo isso irá gerar, segundo Paula Carvalho (1990), uma ampliação assustadora da racionalidade técnica e seus traços: produtivismo, eficiência, ofelimidade, progresso.

Para que a racionalidade técnica seja definida é preciso um amplo conceito de regras que, posteriormente, visará obter o controle de qualquer intervenção.

Godelier (apud PAULA CARVALHO, 1990) define praxeologia exatamente como alógica da ação racional e Maffesoli (1978) a define como a lógica social da dominação. Aescola passa ser o agente da endoculturação repressiva.

Essa lógica educativa da dominação praxeológica vai ao encontro daquilo que Maffesoli (1987) designa como político econômico, engendrando uma dinâmica sócio-psicoorganizacional regida pela dimensão macroestrutural. Em contrapartida, encontramos como 
alternatividade organizacional o trabalho realizado nos microgrupos e a "educação fática" cunhada por Paula Carvalho (1987). A educação precisa ser vista como um conjunto de todas as práticas simbólicas, a educação é basal. As diferenças, conflitorialidades coexistem, e permeiam os grupos que estão presentes o tempo todo na escola.

Numa gestão escolar em que a praxeologia é a mediadora, o imaginário social estará subordinado, reprimido e submetido à racionalização.

Como observamos, para que essa realidade sofra mudanças é necessário um novo paradigma. No entanto, reparadigmatizar não é algo fácil; pelo contrário, é algo complexo, pois é preciso mudança de quadros de pensamento.

\section{Paradigma Holonômico e Educação Fática}

O paradigma holonômico, que adotamos, se apoia na razão aberta e complexa. E “dá asas" a "cultura dos sonhos", à "cultura dos sentimentos e das imagens", pois acreditaque é através da psique humana e dos pequenos grupos que se poderá ter odesenvolvimento de matrizes criativas e reflexivas. Por isso, é imprescindível conhecer a experiênciados pequenos grupos para começar a compreender a experiência do imaginário.

Durand (apud BADIA, 2003) afirma que o imaginário não é uma disciplina, mas sim um tecido conjuntivo entre as disciplinas, é uma convocação ao Sentido. O imaginário instaura o universo de existência e de ação das ciências humanas. O imaginário é "o capital inconsciente de gestos dos sapiens", é "o conjunto das polissemias simbólicascomo conjuntos psicoculturais" e trata-se do universo das representações coletivas classificando e organizando simbolicamente os mapas de realidade e de consciência dosgrupos sociais. Essas representações são configuradas como práticas simbólicas eorganizacionais.

Paula Carvalho (1990) evidencia que os grupos sociais desenvolvem uma dimensão organizacional e educativa. Não existe somente uma forma de educação; aeducação é ampla, é realizada na escola, mas também por todos os grupos sociais. Desta forma, o autor irá mostrar que a educação é prática basal de sutura dasdemais práticas sociais. Os grupos sociais estão presentes nas escolas nomulticulturalismo que constitui a cultura escolar como culturas escolares.

O perigo que podemos constatar é justamente que a escola queira, através da teoria dos currículos, programas e avaliações, a homogeneização desses grupos, o que sabemos é desastroso, poisassim, o "eu" será mortificado para que então a instituiçãototal surja: forte, afirmando-se em tudo e a todos: "eu sei o que é melhor para você", "siga este caminho", eu 
“dou a receita e você a segue corretamente". Tudo issonuma obsessiva intervenção, querendo deixar as "coisas ordenadas".

Seria interessante observar que a educação fática que está em contraposição à educação praxeológica e a favor da revalorização das funções da imaginação simbólicaemergirá a partir da ruptura dos códigos expressivos, que são os "movimentos doimaginário".

Então surge uma pergunta: O que deve ser entendido por "organização educativa"?

É preciso saber que as organizações são grupos semiestruturados que coincidem com o momento instituinte da dinâmica sócio organizacional e que o ato de organizar existeem moldes arquetípicos. Em suma, a organização educativa será, como diz Morin (1987), uma formação de sensibilidades de teor "em-ciclo-pédico" colocando em contato aquilo que estava disjunto, fazendo tudo se comunicar numa dimensãointerdisciplinar de contato e de sutura. Isso é a "educação fática".

O paradigma clássico trata da simplificação, disjunção, exclusão e separa o sujeito cognoscente do objeto conhecido, ou seja, separa o sujeito e o mundo, procurando operacionalizar. Morgan (apud BADIA, 2003, p. 14), fala em “[...] metáfora da máquina [...]”: a construção da cultura pela máquina do trabalho e pelaorganização burocrática das atividades humanas. A praxeologia bloqueia a ação comunicativa entre os grupos; temos, assim, uma concepção de cultura regida pela "razão prática" e que se confunde com os códigos enormas uma concepção de educação praxeológica que, formará para o "desemprego estrutural" e forjará uma concepção entrópica deorganização. Sendo assim, podemos afirmar que abordagens clássicas unem - se ao "projeto da modernidade" e não consideram a ambivalência e a conflitorialidade existentes no universo antropo - sócio - organizacional.

Já as abordagens holonômicas vinculam-se ao "colapso do projeto da modernidade" e fazem saltar aos nossos olhos essa ambivalência e conflitorialidade, pois dá ênfase a uma ontologia pluralista e contraditorial e a uma epistemologia sintético - compreensiva efenomenológica. A concepção da razão aberta é contemplada, a aprendizagem dá - se pelainterdisciplinaridade, os conceitos, que antes eram considerados incompatíveis eexcludentes, devem ser ligados pela lógica da conflitorialidade através de relações antagonistas, concorrentes, mas possíveis devido à lógica da comunicação conceitual, pluralista (dialógica), lidando com articulações complexas. Existe assim, "a pluralidade dasformas de consciência", como diz Badia (2003, p. 15): 
É a razão desvendada pela psicanálise e pela "imageriementale", como por exemplo a "consciência onírica" e as "imagens hípnicas", que são portas de entrada para o domínio da função e mediçãosimbólica, pois o símbolo é fator de união.

Por isso é que alguns filósofos (da linguagem), como Derrida e Deluze (apud BADIA, 2003), escreveram sobre "clausura dalinguagem" mostrando que, se as representações coletivas são sempre mediadoras, elas seelaboram sempre como linguagem ou linguagens nos sistemas simbólicos. Esses sistemassimbólicos possuem práticas simbólico - organizacionais e dinâmicas educativas. Mas as organizações sociais são vistas como "estruturações afetivas ou vinculares" na educação fática. O que de fato importa é a profundidade dos vínculos simbólicos, afetuais de grupos e indivíduos visando à autonomia.

Assim sendo, não temos acesso direto à presumível existência de uma realidade, mas somente às medições simbólicas que dela falam "por hipótese". Nãopodemos pensar sem a existência de uma língua. Se o paradigma e a "língua ou linguagem"- mudarem, a realidade mudará, ou seja, conforme diz Schütz (apud BADIA, 2002, p. 20), teremos outra apreensão, outro "tipo de âmbito de sentido". Esse relativismo cultural estabelece - se numa "cultura da diferença". Tudo isso em oposição ao "etnocentrismo", que privilegia um determinadoreferencial cultural seguindo-se preconceitos e exclusões.

No universo holonômico ocorre a acolhida do "Outro", pois a cultura é regida pela "razão simbólica e suas formas e práticas" e há uma concepção de "educação fática" e uma concepção neguentrópica de organização onde o alvo é a auto-organização, a autogestão, podendo se alicerçar e construir um "espaço entre-saberes" que promova a pluridisciplinaridade e a transdisciplinaridade.

Por isso, privilegiaremos a "razão cultural", pois esta tem por pressuposto que é a partir da representação simbólica que se começa organizar a esfera de ação. Dessa forma, ela seria, como diz Teixeira (1990, p. 83): "a organizadora do real". Na medida em que o comportamento social dos indivíduos é o resultado de uma pré- compreensão simbólica do real, significa que o universo da mediação simbólicaé considerado como o conjunto de todos os produtos culturais, (linguagem, religião, ciência, arte, mito) e é, portanto, função basal de constituição da ordem social.

As práticas simbólicas constituem o imaginário. Essas práticas são organizacionais e educativas, na medida em que os vínculos vão sendo criados.

O enfoque da razão cultural almeja uma reflexão sobre a concepção de sociedade, de organização e, concomitantemente, de educação. É por isso que as funções da escola precisam 
ser repensadas, pois não dá para continuar considerando-a como mecanismo de controle social. Uma educação com a dimensão simbólica não pode possuir funções somente reprodutoras, pois naturalmente estimulará a participação, criticidade e a criatividade.

Para que esta concepção de educação seja real, é necessário que os educadores tenham uma postura de abertura às novas descobertas e estar ciente de que esta concepção de educação remeterá aos modelos neguentrópicos de organização e estes são complexos.

A utilização do enfoque "da razão cultural" para o estudo da gestão escolar sugerirá uma concepção cada vez mais ampliada de educação que consequentemente conduzirá a aceitação e até mesmo à valorização da alteridade, da diferença. Esta concepção esclarecerá que não existe somente uma maneira adequada de se ensinar ou de se aprender, mas sim, a existência de formas diferenciadas de ensino, educação e aprendizagem, que trazem consigo diferentes maneiras de organização escolar.

Louro (2014a) reconhece a escola como produtora de diferenças, distinções, desigualdades. Visto que, muitas vezes, existe a ocultação e silenciamento de assuntos que envolvam a sexualidade. A formação continuada reflexiva e de possibilidades, justifica-se por ser imperativa à inclusão social. Uma inclusão sem distinções que aspire às pluralidades da criança ao adulto, excluindo-se, portanto, generalizações, regulações e padronizações, as quais produziram e continuam produzindo, distinções, desigualdades e exclusão social, sobretudo, na escola.

É importante enfatizar que a escola é um ambiente que "[...] se aprende a olhar e a se olhar, se aprende a ouvir, a falar e a calar; se aprende a preferir." (LOURO, 2014a, p.61).

Portanto, a reflexão docente sobre suas práticas educacionais, reforços e dicotomias, sugere conforme Louro (2014a) uma percepção criteriosa para as desigualdades, diferenças, sobretudo, para a sexualidade na escola.

\section{Educação Sexual e a formação de educadores reflexivos}

Para discutir nas escolas educação sexual, diversidade e gênero diz ser necessário um professor especializado no assunto, mas onde estão esses profissionais?

Todo e qualquer profissional da educação é responsável pelo envolvimento no processo de formação social, pessoal e crítica do educando, então porque não partir desses profissionais na sala de aula e na escola para trazer questões ligadas à sexualidade. 
Os professores segundo Figueiró (2014) não são mais vistos apenas como transmissores de conhecimentos são vistos também como profissionais que criam e constroem conhecimentos.

O educador desde sua formação inicial deve fazer o exercício da autorreflexão, mesmo que não esteja dentro da sala de aula. Figueiró (2014, p. 4-5) nos diz que:

Não se pode perder de vista, primeiramente, o significado da formação do educador, pois ela envolve tanto a inicial, quanto a continuada, sem, no entanto, restringir-se a estes momentos, uma vez que começa a acontecer antes mesmo da formação inicial e prossegue ao longo de todo o período da prática profissional.

Desta forma é importante que os docentes entendam a emergência de trabalhar as relações de gênero, a diversidade e a sexualidade dentro da escola, junto com a comunidade escolar, e deixar claro o enlace e o comprometimento da educação com a educação sexual.

Nos dias atuais o estouro dos discursos a favor e/ou contraditórios no que diz respeito às relações de gênero e diversidade sexual leva os docentes a discutir isso dentro da escola, a educação sexual, o respeito com e para com o outro são partes do dia a dia dos indivíduos, não existe possibilidades de separar essas instâncias.

Para tanto, é necessário entender os conceitos, as raízes, os fundamentos e os objetivos dessas discussões. Para isso Louro (2014a) nos três primeiros capítulos de seu livro Gênero, sexualidade e educação: uma perspectiva pós-estruturalista, nos apresenta os conceitos e teorias dos estudos feministas e suas implicações na educação dos tempos atuais.

Segundo a autora o conceito de gênero está diretamente ligado à história das lutas do movimento feminista. Na primeira onda do feminismo as mulheres conseguiram o direito ao voto, na segunda onda por volta dos anos 60 começa-se a ter construções teóricas e em 1968 surgem os estudos da mulher.

Com a mulher conquistando e construindo seu lugar social surgem discussões sobre a distinção das funções de homens e mulheres dentro de uma sociedade. Falar que homens e mulheres se diferem na forma biológica se torna inviável, para isso é preciso demonstrar inclusive nas escolas que essa não é a origem da diferenciação, mas é

[...] a forma como essas características são representadas ou valorizadas [desvalorizadas], aquilo que se diz ou se pensa sobre elas que vai construir, efetivamente, o que é feminino ou masculino em uma dada sociedade e em um dado momento histórico. (LOURO, 2014a, p. 25, grifo nosso). 
A autora nos leva a entender o gênero como constituinte da identidade dos sujeitos, sendo assim, as identidades não podem ser consideradas fixas, estáveis. Longe disso, as identidades são percorridas por diferentes discursos, símbolos, representações e práticas, construindo os sujeitos como masculinos e femininos, tirando e colocando estes em seus lugares sociais.

Nesta perspectiva, o professor pode trazer para a sala de aula os conceitos e mostrar aos alunos que os papéis são e estão sendo construídos socialmente, frente a uma sociedade elitizada, branca, heteronormativa, que ditam "regras" ditas únicas e certas a serem seguidas.

Para que isto aconteça se faz necessária a formação continuada do docente, que como dito anteriormente tem sua história de vida pessoal e profissional que deve passar por reflexão e por um aprimoramento da prática profissional.

De acordo com Nóvoa (1997) apud Figueiró (2014), a formação continuada deve gerar resultados na vida do professor, na profissão do professor e na escola.

Para que essa formação seja efetiva são necessários alguns pressupostos. O primeiro é que o professor seja considerado construtor, sujeito de sua própria maneira de ser e agir profissionalmente, onde toda a experiência é considerada e valorizada. O segundo pressuposto é que o professor precisa ter suporte, através de apoio, desafios e estímulos lançados durante o processo de educador. O terceiro é que precisamos considerar a escola como objeto de reflexão e como um local de ação, ou seja, devemos enxergar o professor como um sujeito pensante, reflexivo e que toma decisões, inova, atua e avalia. Por fim, é imprescindível que o professor seja visto como um profissional que produz saberes e não que simplesmente segue técnicas e as transmite de um único modo.

Para Figueiró (2014) é fundamental que a formação continuada tenha ligação com os problemas enfrentados na sala de aula, e um desses "problemas" é a educação sexual, os professores não tem base teórica para se trabalhar a educação sexual sem tabus, considerandoa como essencial para a formação do educando.

A escola reforça as desigualdades e diferenças através das normas impostas socialmente, por exemplo, brinquedos de menina e de menino, filas separadas, entre outras situações que fazem com que a escola produza diferenças. Como destaca Louro (2014b, p. 65), começa nos manuais mais antigos a moldar o corpo da criança.

O modo de sentar e andar, as formas de colocar cadernos e canetas, pés e mãos acabariam por produzir um corpo escolarizado, distinguindo o menino ou a menina que "passara pelos bancos escolares". 
Em relação a essa construção escolar das diferenças, Louro (2014a) nos leva a refletir situações e conceitos que são naturalmente apropriados pelos sujeitos, e nesse ponto a autora nos alerta para questionar o que nos é imposto e ter um olhar de desconfiança, pelos préconceitos que carregam.

De acordo com a autora, a escola ocidental moderna tem um conjunto de normas para o processo de "fabricação" dos sujeitos sendo este quase imperceptível, reforçando e reafirmando as desigualdades e diferenças. Louro (2014b, p. 68) diz:

Currículos, normas, procedimentos de ensino, teorias, linguagem, materiais didáticos, processo de avaliação são, seguramente, loci das diferenças de gênero, sexualidade, etnia, classe [...]. Todas essas dimensões precisam, pois, ser colocadas em questão.

Cabe aqui o educador refletir sobre sua prática educacional, será que reforçamos e/ou produzimos estas dicotomias? É necessário enfrentar os problemas que acontecem dentro das salas de aula, é preciso rever os materiais, reformular práticas, pensar antes de agir, pois segundo Figueiró (2014), é essencial vencer medos e constrangimentos através de atitudes e reflexões próprias.

Algumas atitudes e posicionamentos fixados pela escola ressaltam as diferenças, Louro (2014a) destaca algumas situações como o treino de habilidades manuais para as meninas, a classificação de atividade entre meninos e meninas, a diferenciação dos brinquedos e das atividades esportivas nas aulas de Educação Física, a reprodução de que existe um único modelo de família, a força do poder da linguagem que aparentemente não faz mal a ninguém.

A autora é enfática no que diz respeito à linguagem. Ela nos leva a desnaturalizar algumas ideias que se fixam em nossa cabeça ganhando status de verdades únicas. Louro (2014b, p. 69) nos mostra que, “[...] a linguagem é, seguramente, o campo mais eficaz e persistente - tanto porque ela atravessa e constitui a maioria de nossas práticas, como porque ela nos parece, quase sempre, muito 'natural'."

A linguagem exerce um poder muito forte nos indivíduos, ela não apenas expressa relações, lugares, poderes, ela os institui; não é simplesmente um meio de se comunicar, obter novos conhecimentos, ela produz e fixa diferenças, pré-conceitos. Louro (2014a apud PORTINARI, 1989, p. 18) diz: 
A linguagem é um turbilhão e nos usa muito mais do que nós a usamos. Ela nos carrega. Molda, fixa, modifica, esmaga (seria talvez a depressão: sou esmagada pela palavra) e ressuscita (não há a "palavra da salvação"?).

Pensamos que talvez essa "palavra de salvação" possa partir de dentro da escola, está na mão da educação essa reflexão de si, de aceitar o outro, respeitar, entender, compreender.

\section{Algumas considerações}

Diante da complexidade apresentada, possibilitar aos docentes refletir sobre perspectivas hegemônicas que circunscrevem as relações de gênero e sexualidade em nossa sociedade, favorece (re)significações subjetivas. Assim sendo é essencial que haja a possibilidade da desconstrução social de naturalizações face à sexualidade, gênero, relações de poder e escola.

Louro (2014, p. 81) evidencia que "[...] a sexualidade está na escola porque ela faz parte dos sujeitos, ela não é algo que possa ser desligado ou algo do qual alguém possa se 'despir'."

Com base nos estudos de Figueiró (2014), primeiramente é fundamental ter a consciência de que a educação sexual é tarefa da escola, os fatos acontecem na escola, em segundo plano é imprescindível à formação continuada, prolongada e com assessoria para a prática pedagógica, pois muitos educadores não tiveram contato com a temática na sua formação e dar maior atenção para a história de vida dos professores.

Estamos frente a uma sociedade plural, por este motivo é necessário mostrar aos educandos as diversas famílias, as diversas sexualidades, as relações de gênero, o respeito; temos uma ferramenta espetacular para que isso aconteça podemos usar a linguagem como meio de reflexão e de reconstrução de estereótipos impostos pela cultura de nossa sociedade através de conversas criativas e refletivas sem imposições.

Uma educação que tenha por base o respeito ao outro, pode e deve ser construída na escola.

Paulo Freire (1998), afirma que a educação tem como elemento fundamental, como seu sujeito, o homem que busca, por meio dela, a superação de suas imperfeições, de seu saber relativo. Aqueles que ensinam não estão lidando com um grupo de ignorantes, mas com homens, que possuem um saber tão relativo quanto o deles.

O reconhecimento da complexidade que envolve a temática abordada neste trabalho aponta para a real necessidade de a escola instrumentalizar-se para fornecer informações mais 
precisas para questões que são respondidas indevidamente. A educação é, ou deve ser instrumento dessa ação, na medida em que possibilita ao homem tomar consciência da realidade em que vive e, em consequência, agir para transformar essa realidade.

\section{REFERÊNCIAS}

BADIA, D. D. Paradigma do imaginário e os fundamentos organizacionais da educação. Araraquara: FCLAr, 2003.

BADIA, D. D. Cultura, organização e educação: temática recorrente. Araraquara: FCLAr, 2002.

BRASIL. Ministério da Educação. Secretaria de Educação Fundamental. Parâmetros Curriculares Nacionais: pluralidade cultural e orientação sexual. Brasília, 1997. v.8.

FIGUEIRÓ, M. N. D. Formação de educadores sexuais: adiar não é mais possível. 2.ed.rev.atual. e ampl. Londrina: EDUEL, 2014.

FREIRE, P. Educação e mudança. 22.ed. Rio de Janeiro: Paz e Terra, 1998.

LOURO, G. L. Gênero, sexualidade e educação: uma perspectiva pós-estruturalista. 16.ed. Petrópolis: Vozes, 2014a.

LOURO, G. L. A construção escolar das diferenças. In: LOURO, G. L. Gênero, sexualidade e educação: uma perspectiva pós-estruturalista. 16.ed. Petrópolis: Vozes, 2014b. p.61-91.

MAFFESOLI, M. O tempo das tribos: O declínio do individualismo nas sociedades de massa. Rio de Janeiro: Forense-Universitária, 1987.

MAFFESOLI, M. Lógica da dominação. Rio de Janeiro: J. Zahar, 1978.

MORIN, E. Ciência com consciência. Rio de Janeiro: Bertrand Brasil, 1987.

PAULA CARVALHO, J. C. Antropologia das organizações e educação: um ensaio holonômico. Rio de Janeiro: Imago, 1990.

PAULA CARVALHO, J. C. Estrutura, organização e educação: o imaginário sócioorganizacional e as práticas educativas. In: FISCHMANN, R. (Org.). Escola brasileira: temas e estudos. São Paulo: Atlas, 1987. p.20-35.

PORTINARI, D. O discurso da homossexualidade feminina. São Paulo: Brasiliense. 1989.

TEIXEIRA, M. C. S. Antropologia, cotidiano e educação. Rio de Janeiro: Imago 1990. 


\section{Como referenciar este artigo}

ARGENTI, Paula Camila.; MILANI, Débora Raquel da Costa. Educação sexual e docência: as relações de gênero, a diversidade e a sexualidade dentro da escola. Doxa: Rev. Bras.

Psicol. Educ., Araraquara, v.19, n.2, p. 212-223, jul./dez. 2017. e-ISSN: 2594-8385.

Submetido em: 04/05/2017

Aprovado em: 30/06/2017 